\title{
Impact of Psychosocial Distress on the Quality of Life of Cancer Patients in Two Health Facilities in Cameroon
}

Bachi-Ayukokang Ebob-Anya ( $\square$ bachiayuk123@gmail.com )

University of Buea, South-West Region, Cameroon

Nahyeni Bassah

University of Buea, South-West Region, Cameroon

\section{Research Article}

Keywords: Distress, Quality of Life, Cancer, Cameroon

Posted Date: September 7th, 2021

DOI: https://doi.org/10.21203/rs.3.rs-870525/v1

License: (c) (1) This work is licensed under a Creative Commons Attribution 4.0 International License.

Read Full License 


\section{Abstract}

Background: Psychosocial distress interferes with the ability to cope effectively with cancer, its physical symptoms and treatment. This in turn leads to poor outcomes in patients.

Objective: The aim of this study was to investigate the impact of psychosocial distress on the quality of life of cancer patients in two health facilities in Cameroon.

Methods: This study used a cross-sectional hospital-based design. The study was carried out over a period of three months from July-September 2020. The sample size was 120 cancer patients. A purposive sampling technique was used to recruit participants. Three validated questionnaires were used: DT, HADS and EORTC QLQ-C30 to assess, psychosocial distress, emotional distress and quality of life respectively. Results were presented using descriptive (frequency, percentage, mean) and inferential statistics (Pearson's correlation, ANOVA). Data were analysed with SPSS version 21. All statistics were considered significant at an alpha value set at 0.05 level.

Results: Majority of the patients $83(69.2 \%)$ presented with clinically significant distress, with financial difficulties 87 (72.5\%), fatigue 83 (69.2\%), transportation $73(60.8 \%)$ and difficulties with work/school $69(57.5 \%)$ being the most reported problems. Fifty nine (50.0\%) and 56(47.5\%) had moderate to severe anxiety and depression symptoms respectively. Overall on HADS, 67 patients (56.8\%) presented with emotional distress. The quality of life was fair, with a mean of $52.4 \pm 21.3$. There was a strong statistically significant relationship between psychosocial distress and the quality of life $(P<0.0001)$, wherein psychosocial distress was found to have a negative impact on the quality of life of patients.

Conclusion: Cancer patients do suffer from psychosocial distress which has a negative impact on their quality of life. This is thus a call for concern to health personnel in this setting. The psychosocial domain of cancer patients needs to be assessed for early identification of persons at risk, to better improve the quality of care which they receive and hence their quality of life.

\section{Background}

Cancer care is rapidly becoming a public health concern in sub-Saharan Africa and Cameroon in particular $[1,2]$. The health-care systems of many sub-Saharan countries are struggling to meet the increasing demand caused by the growing number of patients with cancer, since all the necessary components of cancer care are inadequate [1], in spite of these, cancer continues to be given a relatively low public health priority in Africa due to limited resources, lack of awareness and other pressing health problems such as malaria, tuberculosis and HIV/AIDS [3] The high mortality in sub-Saharan Africa is as a result of poor infrastructure, insufficient number of heath care workers, advanced stage presentation, reliance on traditional therapies, few treatment choices and poor compliance [1]. Cancer is not only a series of very different diseases needing complex and multidisciplinary treatment but also a very stressful event with significant psychosocial implications related to physical, emotional, spiritual, and interpersonal dimensions [4]. Quality of life as defined by WHO is an "individuals' perception of their 
position in life in the context of the culture and value systems in which they live and in relation to their goals, expectations, standards and concerns" $[5,6]$. The definition by WHO considers the person's physical and psychological condition, the level of independence, social relationships, personal beliefs, the environment and culture [5]. Care in cancer patients to ensure the attainment of excellent quality of life, encompasses multidimensional care that is, physical, social, psychological and spiritual. Psychosocial distress in cancer patients arises from several factors such as fatigue, pain, anxiety, fear, treatment options, difficulty in transportation, changes in role relationships, physical limitation, fear of recurrence, disappointing social support [7]. Thus it is of utmost importance to identify the presence of psychosocial distress in cancer patients, and its effect on their quality of life in our setting. This will serve as a baseline to further improve the quality of care this special population receives in our setting, hence, improving their quality of life.

\section{Hypothesis}

Psychosocial distress has a negative impact on the quality of life of cancer patients being managed in two health facilities in Cameroon.

\section{Methods}

Aim: To investigate the impact of psychosocial distress on the quality of life of cancer patients

Study design: the study was a descriptive cross-sectional hospital-based study of cancer patients. This design was used because there are no adequate studies in Cameroon on the magnitude and correlates of psychosocial distress on the quality of life of cancer patients to guide the development of effective interventions to improve the health of patients. The study was carried out from 1st July 2020 to 30th September 2020 in the Douala General Hospital and Cameroon Oncology Center Bekoko.

Setting: the study was carried out at the Douala General Hospital and Cameroon Oncology Center Bekoko, both in the Economic capital of Cameroon, Douala. The Douala General Hospital is government owned institution and serves as the largest referral center for cancer care and treatment in Cameroon. The Cameron Oncology Centre is a new private owned institution, offering both chemotherapy and radiotherapy services, making it the second institution in the nation offering radiotherapy services, after the Douala General Hospital at the moment.

Sample: The desired participants were identified cancer patients who were 18 years and above and gave their consent. Those who were excluded were patient in distress/serious condition, inability to speak or understand English, French or Pidgin and those with/had been diagnosed with psychological problems/receiving specialized psychological treatment. A total of 152 patients were approached, however only 120 participated in the study.

Study instruments: Distress was assessed using the national comprehensive cancer network (NCCN) distress thermometer (DT), which is self-rated from 0 (no distress) to 10 (extreme distress) based on 
patients' report on how the past week was. The DT has a cut-off score of 4 , thus a score of $\geq 4$ is indicative of clinical evidence of moderate to severe distress. Also, the tool includes a checklist of 35 practical, physical, family, emotional, and spiritual concerns over the past week that are perceived causes of distress [8]. The tool has a good reliability and validity and has been extensively used in studies to assess distress levels of patients and caregiver [9-13].

Emotional distress was evaluated using the hospital anxiety and depression scale (HADS), is a selfassessment scale which was developed by Zigmond and Snaith [14] in 1983. This 14-item scale has good reliability and validity and has been extensively used in studies of cancer patients and caregivers [15-17]. It consists of two sub-scales; that is an anxiety scale and a depression scale each with a total score of 21, which assesses patients' experiences during the past week. Its cut-off on an individual scale is $\geq 8$, scores of $8-10$ represent moderate symptoms and $\geq 11$ representing severe symptoms on either scale. Combing both sub-scales gives an overall score on 42 , which measures emotional distress with a cut off score of $\geq 15$ indicating moderate to severe emotional distress. The hospital anxiety scale is not a definitive diagnostic tool for either anxiety or depression. It serves as an initial tool to identify persons at risk for further evaluation.

The European Organization for Research and Treatment of Cancer Quality of Life Questionnaire (EORTC QLQ-C30) was used to measure the primary outcome for cancer patients, that is, the quality of life. It incorporates a global health status, five functional scales (physical, role, cognitive, emotional, and social functioning) and a symptom scales. For the functioning scales and global QOL higher scores indicate better functioning; for the symptom scales higher scores indicate higher symptom burden. In general total score ranges from 1-100 and measures quality of life of patients during the past week [16, 18-21].

Data analysis: Data were entered into Epi data version 3.1 and analysed with SPSS Version 21. The data was analysed using both descriptive \{frequency count, percentage and mean, standard deviation (SD)\} and inferential statistics (Pearson's correlation, one-way ANOVA) for significance testing. Finally, all statistics were considered significant at alpha level 0.05 .

Ethical consideration: Administrative approval was obtained from the Faculty of Health Sciences, University of Buea. Also, ethical clearance from the Faculty of Health Sciences Institutional Review Board was granted (2020/1178-03/UB/SG/IRB/FHS). These were used to gain access to the study hospitals. Once all administrative formalities were settled, participant recruitment began. Data collection commenced immediately consent was granted by participants. Also, participants' autonomy was ensured and they were made to know they had the freedom to withdraw at any time. Other ethical values which were ensured throughout the study included confidentiality, beneficence, non-maleficence and honesty.

\section{Results}

The mean age of patients was $46.1 \pm 13.1$ years, with values ranging from $18-73$ years. Majority of the patients were female $92(76.7 \%)$ and married 69 (57.5\%). The most frequent occurring cancers were breast 50 (41.7\%) and urogenital 39 (32.5\%) cancers (Table 1). Urogenital cancers including cervical, 
prostrate and urethral cancers. Thirteen (10.8\%) were at stage 1 of their disease, $14(11.7 \%)$ at stage 2,13 (10.8\%) at stage $3,5(4.2 \%)$ at stage 4 and $75(62.5 \%)$ were not aware of their cancer stage. Majority of the patients had children 105 (87.5\%) and 21 (17.5\%) had other comorbidities (Table 1). 
Table 1

Socio-demographic characteristics of patients

\begin{tabular}{|c|c|c|c|c|}
\hline $\mathrm{S} / \mathrm{N}$ & & & Frequency & Percentage \\
\hline \multirow[t]{2}{*}{1} & \multirow[t]{2}{*}{ Gender } & Female & 92 & 76.7 \\
\hline & & Male & 28 & 23.3 \\
\hline \multirow[t]{3}{*}{2} & \multirow[t]{3}{*}{ Age category } & $18-30$ & 14 & 11.7 \\
\hline & & $31-50$ & 56 & 46.7 \\
\hline & & $>50$ & 50 & 41.7 \\
\hline \multirow[t]{3}{*}{3} & \multirow[t]{3}{*}{ Marital status } & Single & 41 & 32.4 \\
\hline & & Married & 69 & 57.5 \\
\hline & & Widowed/divorced & 10 & 8.3 \\
\hline \multirow[t]{4}{*}{4} & \multirow[t]{4}{*}{ Level of education } & Primary & 23 & 19.2 \\
\hline & & Secondary & 56 & 46.7 \\
\hline & & Tertiary & 39 & 32.5 \\
\hline & & None & 2 & 1.7 \\
\hline \multirow[t]{3}{*}{5} & \multirow[t]{3}{*}{ Employment status } & Employed & 71 & 59.2 \\
\hline & & Unemployed & 42 & 35.0 \\
\hline & & Retired & 7 & 5.8 \\
\hline \multirow[t]{6}{*}{6} & \multirow[t]{6}{*}{ Monthly income } & $<178.70 \$$ & 20 & 16.7 \\
\hline & & $178.70 \$-893.52 \$$ & 26 & 21.7 \\
\hline & & $>893.52 \$$ & 5 & 4.2 \\
\hline & & Nothing & 40 & 33.3 \\
\hline & & Varies & 12 & 10.0 \\
\hline & & Unanswered & 17 & 14.2 \\
\hline \multirow[t]{5}{*}{7} & \multirow[t]{5}{*}{ Location of cancer } & Breast & 50 & 41.7 \\
\hline & & Head and neck & 19 & 15.8 \\
\hline & & Urogenital & 39 & 32.5 \\
\hline & & Gastrointestinal & 6 & 5.0 \\
\hline & & Others & 6 & 5.0 \\
\hline
\end{tabular}




\begin{tabular}{|llll|}
\hline S/N & & Frequency & Percentage \\
\hline 8 Mode of treatment & Radiotherapy & 15 & 12.5 \\
\cline { 2 - 4 } & Radiotherapy/Chemotherapy & 27 & 22.5 \\
\cline { 2 - 3 } & Radiotherapy/Surgery & 6 & 5.0 \\
\hline Radiotherapy/Chemotherapy/Surgery & 25 & 20.8 \\
\hline Chemotherapy & 23 & 19.2 \\
\hline Chemotherapy/Surgery & 12 & 10.0 \\
& Surgery & 3 & 2.5 \\
\hline None & 9 & 6.7 \\
\hline
\end{tabular}

For psychosocial distress, the mean distress level was $4.5 \pm 2.7$ with values ranging from 0 to 10 . Majority of the patients $83(69.2 \%)$ had significant clinical distress as they had a score of $\geq 4$ (cut off), while $37(30.8 \%)$ were below the cut off score. The most reported problems by patients were; insurance/finance 87 (72.5\%), fatigue $83(69.2 \%)$, transport $73(60.8 \%)$, work/school $69(57.5 \%)$, loss of interest in usual activities 67 (55.8\%), worry 62 (51.7\%), sleep $62(51.7 \%)$, pain 58 (48.3\%), appearance 55 (45.8\%), waiting time $53(44.2 \%)$ and child care 51 (42.5\%).

The mean anxiety score was $7.7 \pm 3.6$ with scores ranging from $0-17$. Fifty-nine (50.0\%) patients had mild, $32(27.1 \%)$ had moderate and $27(22.9 \%)$ had severe anxiety symptoms. Thus $59(50.0 \%)$ of the patients had scores in the moderate to severe category. On the depression scale, the mean score was 7.6 \pm 4.1 with scores ranging from $0-19$. Sixty-two $(52.5 \%)$ had mild, $29(24.6 \%)$ had moderate and $27(22.9 \%)$ had severe depression symptoms. Thus $56(47.5 \%)$ of the patients had scores in the moderate to severe category. The mean of the overall scale was $15.4 \pm 6.7$ with scores ranging from $3-32$. Majority of the patients $67(56.8 \%)$ had an overall score above the cut off score $\geq 15$, while $51(43.2 \%)$ were below the cut off score.

The mean score for the general health status (quality of life) was $52.4 \pm 21.3$ out of 100 , and values ranged from 0-100. On the functional scale, cognitive, physical and emotional functioning had the highest mean scores $78.9 \pm 23.0,73.4 \pm 23.5$ and $72.9 \pm 23.6$ respectively out of 100 . Cognitive functioning, concerned the presence of difficulty to remember things and concentrate on things like reading or watching television. Physical functioning concerned difficulty doing strenuous activities, taking long walks, taking short walks, need to stay in bed or a chair and need with toileting activities. Emotional functioning concerned feeling tensed, worried, irritable and depressed. Social functioning had the lowest mean value $49.0 \pm 38.0$, which concerned family life and social activities. On the symptom scale, financial difficulties had the highest mean score $69.2 \pm 36.4$, followed by fatigue $39.1 \pm 26.3$ (Table 2). 
Table 2

Mean and standard deviation of EORTC QLQ-C30

S/N Domain Mean SD Minimum Maximum

\section{Global health status}

$\begin{array}{llllll}1 & \text { Global health status/QOL } & 52.4 & 21.3 & 0 & 100\end{array}$

\section{Functional scale}

\begin{tabular}{|llllll|}
\hline 2 & Physical functioning & 73.4 & 23.4 & 7 & 100 \\
\hline 3 & Role functioning & 59.6 & 37.9 & 0 & 100 \\
\hline 5 & Emotional functioning & 72.9 & 23.6 & 0 & 100 \\
\hline 6 & Cognitive functioning & 78.9 & 23.0 & 0 & 100 \\
\hline Symptom scale & 49.0 & 38.0 & 0 & 100 \\
\hline 7 & Fatigue & & & & \\
\hline 8 & Nausea and vomiting & 39.1 & 26.3 & 0 & 100 \\
\hline 9 & Pain & 12.9 & 20.2 & 0 & 100 \\
\hline 10 & Dyspnoea & 36.8 & 35.4 & 0 & 100 \\
\hline 11 & Insomnia & 17.8 & 25.2 & 0 & 100 \\
\hline 12 & Appetite loss & 34.4 & 37.9 & 0 & 100 \\
\hline 13 & Constipation & 21.7 & 31.9 & 0 & 100 \\
\hline 14 & Diarrhoea & 16.9 & 28.0 & 0 & 67 \\
\hline 15 & Financial difficulties & 6.1 & 15.6 & 0 & 100 \\
\hline * EORTC QLQ-C30: European Organization for Research and Treatment of Cancer Quality of Life \\
Questionnaire Version 30, SD: Standard Deviation, QOL: Quality of Life.
\end{tabular}

Upon analysis with one-way ANOVA to identify associations between distress levels and the various domains of quality of life, the following were identified (Table 3); Anxiety was found to have a strong association with emotional functioning, where $P<0.0001$. Also, a statistical significant association was found between anxiety quality of life, where $P<0.05$. On the symptom scale, it was statistically associated with pain, insomnia and financial difficulties, where $P<0.05$.

Depression was seen to a have a strong statistical relationship with quality of life, where $P<0.0001$. On the functional scale, depression was associated with physical, role, emotional and social functioning 
where $\mathrm{P}<0.05$. On the symptom scale, there was a statistically significant relationship between depression and fatigue, dyspnoea and insomnia where $\mathrm{P}<0.05$.

As concerns emotional distress, a strong statistically significant association was found with quality of life, emotional functioning and pain, where $P<0.0001$. Also, it was associated with fatigue, insomnia, loss of appetite and constipation, where $\mathrm{P}<0.05$.

For psychosocial distress, a strong statistical association was found between with quality of life and fatigue, where $P<0.0001$. Psychosocial distress was also associated with all aspects on the functional scale, insomnia and financial difficulties, where $\mathrm{P}<0.05$. 
Table 3

Factors Associated With Quality Of Life of Patients

\begin{tabular}{|c|c|c|c|c|c|c|c|c|c|}
\hline \multirow[t]{2}{*}{$\mathrm{S} / \mathrm{N}$} & \multirow[t]{2}{*}{ Domain } & \multicolumn{2}{|c|}{$\operatorname{HADS}(\mathrm{A})$} & \multicolumn{2}{|c|}{ HADS (D) } & \multicolumn{2}{|c|}{ HADS (overall) } & \multicolumn{2}{|c|}{$\begin{array}{l}\text { Psychosocial } \\
\text { distress }\end{array}$} \\
\hline & & $\mathbf{F}$ & $\mathbf{P}$ & $\mathbf{F}$ & $\mathbf{P}$ & $\mathbf{F}$ & $\mathbf{P}$ & $\mathbf{F}$ & $\mathbf{P}$ \\
\hline \multicolumn{10}{|c|}{ Global health status } \\
\hline 1 & $\begin{array}{l}\text { Global health } \\
\text { status/QOL }\end{array}$ & 1.985 & 0.021 & 3.212 & 0.000 & 3.226 & 0.000 & 4.060 & 0.000 \\
\hline \multicolumn{10}{|c|}{ Functional scale } \\
\hline 2 & Physical functioning & 1.104 & 0.362 & 2.712 & 0.001 & 1.570 & 0.060 & 3.100 & 0.002 \\
\hline 3 & Role functioning & 1.613 & 0.079 & 2.317 & 0.004 & 1.098 & 0.360 & 2.529 & 0.009 \\
\hline 4 & $\begin{array}{l}\text { Emotional } \\
\text { functioning }\end{array}$ & 5.511 & 0.000 & 2.079 & 0.011 & 2.702 & 0.000 & 3.000 & 0.002 \\
\hline 5 & Cognitive functioning & 1.278 & 0.226 & 1.531 & 0.092 & 1.060 & 0.404 & 2.722 & 0.005 \\
\hline 6 & Social functioning & 1.450 & 0.134 & 1.860 & 0.026 & 1.482 & 0.087 & 2.739 & 0.005 \\
\hline \multicolumn{10}{|c|}{ Symptom scale } \\
\hline 7 & Fatigue & 1.515 & 0.109 & 1.855 & 0.027 & 2.150 & 0.004 & 4.040 & 0.000 \\
\hline 8 & Nausea and vomiting & 1.238 & 0.253 & 1.518 & 0.096 & 1.473 & 0.090 & 1.210 & 0.293 \\
\hline 9 & Pain & 2.162 & 0.011 & 1.671 & 0.055 & 2.884 & 0.000 & 1.294 & 0.243 \\
\hline 10 & Dyspnoea & 0.536 & 0.922 & 2.030 & 0.013 & 1.182 & 0.275 & 2.909 & 0.003 \\
\hline 11 & Insomnia & 1.892 & 0.030 & 1.913 & 0.021 & 2.281 & 0.002 & 2.610 & 0.007 \\
\hline 12 & Appetite loss & 1.377 & 0.169 & 1.081 & 0.382 & 2.447 & 0.001 & 1.359 & 0.209 \\
\hline 13 & Constipation & 1.484 & 0.121 & 0.473 & 0.968 & 1.750 & 0.027 & 0.657 & 0.576 \\
\hline 14 & Diarrhoea & 1.092 & 0.373 & 0.663 & 0.846 & 0.878 & 0.639 & 1.158 & 0.327 \\
\hline 15 & Financial difficulties & 2.094 & 0.014 & 1.673 & 0.054 & 1.000 & 0.478 & 1.960 & 0.045 \\
\hline
\end{tabular}

There was a strong significant negative correlation between quality of life and psychosocial distress, depression and emotional distress, where $P<0.0001$. Also, there was a significant negative correlation between anxiety and quality of life, where $\mathrm{P}<0.05$ (Table 4). Thus, as psychosocial distress, anxiety, depression and emotional distress increase, the quality of life of patients reduces. Given that higher scores on the quality of life scale indicate better quality of life and lower scores, poor quality of life. Thus, there is sufficient evidence to support the claim that psychosocial and emotional distress have a negative 
impact on the quality of life of patients. Also, correlating psychosocial distress and emotional distress, there was a strong positive correlation with $\mathrm{P}<0.0001$ (Table 4). Thus as emotional distress in patients' increases emotional distress too increases, providing additional support to the impact of psychosocial distress on the health of patients.

Table 4

Correlation between Psychosocial and Emotional Distress and Quality Of Life

\begin{tabular}{|llll|}
\hline S/N & Comparison & Correlation coefficient (r) & P value \\
\hline Patients & & \\
\hline 1 & DT vs. EORTC QLQ-C30 & $-0.374^{* \star}$ & 0.000 \\
\hline 2 & Anxiety vs. EORTC QLQ-C30 & $-0.289^{* *}$ & 0.002 \\
\hline 4 & Depression vs. EORTC QLQ-C30 & $-0.472^{* *}$ & 0.000 \\
\hline 5 & HADS (overall) vs. EORTC QLQ-C30 & $-0.448^{* *}$ & 0.000 \\
\hline $\begin{array}{l}* \text { DT: Distress Thermometer, EORTC QLQ-C30: European } \\
\text { Cancer Quality of Life Questionnaire Version 30, HADS: Hospital Anxiety and Depression Scale. }\end{array}$ \\
\hline
\end{tabular}

\section{Discussion}

The mean age of this study was lower than that reported in previous studies $[43-44,47][10,15-16]$, implying the patients in this study were younger those in other studies. Most of the patients were employed, contrary to reports by previous studies $[43,46,48,54][9,15,17,22]$. This goes to show that despite the presence of the disease many patients were still able to hold down their jobs. Similar to previous studies [12, 22], breast cancer was the most frequent occurring cancer. Strangely, majority of the patients were unaware of the stage of their cancer which was not the case with other studies [12, 23]. This stirs up worries as to how much information is given to these patients by health personnel. In depth information sharing between health personnel and patients is not very common practice in our setting, as health personnel often hold monopoly to patients' information. Most patients received combination therapy as method of management of their cancer, which was the case with a previous study in Morocco by El Fakir et al [19].

The NCCN guidelines recommend the screening for distress as the 6th vital sign as a first step to identify those who will benefit from further assessment, in order to maximize health and wellbeing [8]. For patients, the fact that more than half of the patients were above the cut off score for significant clinical distress indicates that it is a problem which needs to be looked into, this finding is similar to that of Meeker et al [11]. The prevalence of this study was however higher than what was reported in those studies $[10,12-13,22]$. It could be said that patients in this study suffered more than patients elsewhere, 
given that we are in a resource poor setting. Another reason for the high prevalence could be the fact that this study considered the cut off score of 4 as per the NCCN manual, while these other studies considered $\geq 5$ as cut off. Thereby reducing the proportion of patients who presented with distress. As reported by other studies, distress is normal response to cancer but the emotional aspect of distress may be related to quality of life, adherence to treatment and satisfaction with care [24]. The most indicated problems faced by patients included fatigue, worry, sleep, nervousness, pain, fear and financial difficulties $[9,11-12,25]$. These problems were also reported by most of the patients in our study. This implies that patients in our settings are not very different from others as they have similar problems. However in this study, financial difficulties took the lead position, followed by fatigue which was not the case with other studies [9]. This could be attributed to the fact that treatment of cancer is financially demanding and most persons in our setting are not insured. Hence, though most of the patients were employed, they still had difficulties keeping up with the financial burden of the illness. This gives enough reason for patients to be in distress, with a lot of uncertainties surrounding the continuation or even commencement of treatment because of finances. Meeker et al [11] in their study recommended that interventions aimed at improving distress in patients should also focus on financial distress, by helping patients understand and manage financial obligations and develop financial literacy skills. Also, fatigue is one of the most common symptoms in cancer patients, especially for those undergoing radiation therapy or chemotherapy [16]. This is the case with our study, wherein almost all the patients were being treated with either chemotherapy or radiation therapy or both.

Emotional distress in particular has been one of the domains of distress which has been a focus for previous studies as this has always been associated with the diagnosis of cancer [15-16]. Not only is it a call for concern at the time of diagnosis, but with advancement in treatment modalities and longer survival rates there is increase in the emotional needs of the patients [15]. This is so because of the constant uncertainties surrounding the disease as it progresses and the potential outcomes. To this, cancer has been associated with a reduction in psychological well-being, quality of life, interpersonal relationships, and optimism [26]. Patient are often scared and worried, giving rise to psychological needs. Thus early recognition of the emotional requirements of patients, decreases the cost burden of cancer treatment but at the same time improves quality of life [15]. In this study, a high prevalence of emotional distress in patients was seen when compared to other studies [15-17]. This serves as an indication that the emotional health of patients' needs to be considered in the care plan. It cannot be overstressed the need for a sound psychological domain. Patients in emotional distress are at risk of developing full blown psychiatric disorders. This in the long run affects the treatment of the disease as patients cannot be fully compliant with care, affecting disease outcomes. Thus the prevalence of emotional distress should be an eye opener to heath personnel in our setting to initiate routine screening for patients, in order to identify causes and promptly institute interventions to eliminate these causes. Given that emotional distress can arise at any time along the illness trajectory. This will result in better treatment outcomes as their state of mind will be stable, enabling them combat the illness by complying with treatment. It has been stated that the presence of psychological distress is a risk factor for noncompliance to treatment $[17,26]$. 
Assessment of quality of life is a very important factor for holistic care, since it provides an overall status of the patients' health without disrupting clinical routine [18]. Our findings showed that the quality of life of the patients in our study was fair. The mean overall quality of life score in our study was higher than that reported in previous studies [20-21], probably because their studies included only breast cancer patients and was carried out in Iran where contextual factors could have influenced participants' perception of their general health. However, our mean value was lower compared to other studies $[16,18-$ 19]. This implies that patients elsewhere had better quality of life than the patients in this study. This highlights that, more needs to be done to improve the quality of care which patients receive thereby improving quality of life. The worst scores on the symptom scale of the QLQ-C30 was financial difficulties, followed by fatigue, this report is consistent with that by Fakir et al., in Morocco [19]. This goes in line with the findings on the DT thus, pointing out that these two factors need to be handled while caring for patients. The impact of the financial burden stands out throughout other this study and that of Meeker et al [11]. In our setting, the practice of insurance is not very common and bearing in mind how costly treatment for cancer is, the financial burden of the treatment of cancer falls back to the patient and his/her family. In the study by Meeker et al [11], only $29 \%$ of the patients reported high levels of financial distress, this could be as a result of the fact that all the patients in their study were insured. However, despite all patients being insured, financial distress was still a problem, showing the extent of the effect of financial burden. This study also revealed that, the general quality of life was strongly correlated with psychosocial distress, anxiety, depression and emotional distress, this was also reported in a previous study [16]. Also, psychosocial distress, anxiety, depression and emotional distress affected other aspects on the sub scales of quality of life [16]. This goes to support the importance a multidimensional method of care in dealing with cancer patients. Overall, there is a need for an improvement in the care which cancer patients receive as this study revealed that all major aspects looked at were affected, wherein psychosocial and emotional distress had negative impacts on quality of life. Thus, a wake-up call to health personnel dealing with the cancer patients to re-evaluate management strategies.

\section{Conclusion}

A good majority of the patients presented with psychosocial and emotional distress. The quality of life of patients was seen to be fair. There was a strong association between the psychosocial distress, anxiety, depression, emotional distress and quality of life. This is indicative that there is a need for improvement of the quality of care which patients receive from the health care system. That is, regular assessment of the psychosocial and emotional domain of the patients during contact, in order to early identify problems and institute prompt interventions. This will improve the overall quality of care which patients receive thereby improving their quality of life.

\section{Abbreviations}

DT: Distress Thermometer, HADS: Hospital Anxiety and Depression Scale, EORTC QLQ-C30 European Organization for Research and Treatment of Cancer Quality of Life Questionnaire Version 30, ANOVA: 
Analysis of Variance, SPSS: Statistical Package for the Social Sciences, WHO: World Health Organization, NCCN: National Comprehensive Cancer Network, SD: Standard Deviation.

\section{Declarations}

\section{Ethics approval and consent to participate}

The research had been conducted in accordance with the Declaration of Helsinki. Ethical approval was granted by the Faculty of Health Sciences Institutional Review Board (2020/1178-03/UB/SG/IRB/FHS). Participant were informed both orally and in writing about the study objective, as well as their right to withdraw from the study at any time. All study participants provided signed informed consent for study participation.

\section{Consent for publication}

Not applicable.

\section{Availability of data and materials}

The dataset used for the current study are available from the corresponding author on reasonable request.

\section{Competing interests}

The authors declare that they have no competing interests.

\section{Funding}

The study was funded from the authors' personal funds.

\section{Authors' contributions}

BA and NB, participated in the methodological assessment and design of the study. BA collected and analysed the data under the academic supervision of NB. BA wrote the initial draft of this paper and NB gave comments on all the subsequent and final version of the paper. All authors read and approved the final manuscript.

\section{Acknowledgements}

We thank the health care facilities for granting us access to their institutions. Also, we are grateful to the cancer patients who took out time to be part of this study, despite their health state.

\section{References}


1. Kingham TP, Alatise OI, Vanderpuye V, Casper C, Abantanga FA, Kamara TB, et al. Treatment of cancer in sub-Saharan Africa. Lancet Oncol. 2013 Apr;14(4):e158-167.

2. EnowOrock GE, Ndom P, Doh AS. Current cancer incidence and trends in Yaounde, Cameroon. Oncol Gastroenterol Hepatol Rep. 2012;26;1:58-63.

3. Parkin DM, Ferlay J, Jemal A, Borok M, Manraj SS, N'da GG et al. Cancer in Sub-Saharan Africa [Internet]. [cited $2021 \mathrm{Feb}$ 20]. Available from: https://publications.iarc.fr/Book-And-ReportSeries/larc-Scientific-Publications/Cancer-In-Sub-Saharan-Africa-2018

4. Grassi L, Spiegel D, Riba M. Advancing psychosocial care in cancer patients. F1000Research. 2017;6.

5. Pinto S, Fumincelli L, Mazzo A, Caldeira S, Martins JC. Comfort, well-being and quality of life: Discussion of the differences and similarities among the concepts. Porto Biomed J. 2017;2(1):6-12.

6. World Health Organization. Division of Mental Health and Prevention of Substance Abuse. (1997) . WHOQOL : measuring quality of life. World Health Organization. Available from https://apps.who.int/iris/handle/10665/63482

7. Taghizadeh A, Pourali L, Vaziri Z, Saedi HR, Behdani F, Amel R. Psychological Distress in Cancer Patients. Middle East J Cancer. 2018;9(2):143-9.

8. Riba MB, Donovan KA, Andersen B, Braun li, Breitbart WS, Brewer BW, et al. Distress Management, Version 3.2019, NCCN Clinical Practice Guidelines in Oncology. J Natl Compr Canc Netw. 2019;17(10):1229-49.

9. Srikanthan A, Leung B, Shokoohi A, Smrke A, Bates A, Ho C. Psychosocial Distress Scores and Needs among Newly Diagnosed Sarcoma Patients: A Provincial Experience. Sarcoma. 2019; 5302639.

10. Giese-Davis J, Waller A, Carlson LE, Groff S, Zhong L, Neri E, et al. Screening for distress, the 6th vital sign: common problems in cancer outpatients over one year in usual care: associations with marital status, sex, and age. BMC Cancer. 2012;12:441.

11. Meeker CR, Geynisman DM, Egleston BL, Hall MJ, Mechanic KY, Bilusic M, et al. Relationships Among Financial Distress, Emotional Distress, and Overall Distress in Insured Patients With Cancer. J Oncol Pract. 2016 Jul;12(7):e755-764.

12. Mehnert A, Hartung TJ, Friedrich M, Vehling S, Brähler E, Härter $M$, et al. One in two cancer patients is significantly distressed: Prevalence and indicators of distress. Psychooncology. 2018 Jan;27(1):7582.

13. Loquai C, Scheurich V, Syring N, Schmidtmann I, Rietz S, Werner A, et al. Screening for Distress in Routine Oncological Care-A Survey in 520 Melanoma Patients. PLOS ONE. 2013;8(7):e66800.

14. Zigmond AS, Snaith RP. The Hospital Anxiety and Depression Scale. Acta Psychiatr Scand. 1983;67(6):361-70.

15. Manjeet SS, Rathod J, Maidapwad S. (2014). Prevalence of Emotional Distress in Cancer Patients. IOSR-JDMS, 13(6):09-14.

16. Salvetti M de G, Machado CSP, Donato SCT, Silva AM da. Prevalence of symptoms and quality of life of cancer patients. Rev Bras Enferm. 2020;73(2):e20180287. 
17. Kim GM, Kim SJ, Song SK, Kim HR, Kang BD, Noh SH, et al. Prevalence and prognostic implications of psychological distress in patients with gastric cancer. BMC Cancer. 2017;17:283.

18. Konstantinidis T, Linardakis M, Samonis G, Philalithis A. Quality of life of patients with advanced cancer treated in a regional hospital in Greece. Hippokratia. 2016;20(2):139-46.

19. El Fakir S, El Rhazi K, Zidouh A, Bennani M, Benider A, Errihani H, et al. Health-Related Quality of Life among Breast Cancer Patients and Influencing Factors in Morocco. Asian Pac J Cancer Prev APJCP. 2016;17(12):5063-9.

20. Saleha SB, Shakeel A, Shumaila E, Shazia R, Rashid R, Ibrahim M. An Assessment of Quality of Life in Breast Cancer Patients Using EORTC QLQ C30/+Br23 Questionnaire. International Journal of Cancer Management. 2010;3(2): 98-104.

21. Sheikhalipour Z, Ghahramanian A, Fateh A, Ghiahi R, Onyeka TC. Quality of Life in Women with Cancer and Its Influencing Factors. J Caring Sci. 2019;8(1):9-15.

22. Rajeshwari A, Revathi R, Prasad N, Michelle N. Assessment of Distress among Patients and Primary Caregivers: Findings from a Chemotherapy Outpatient Unit. Indian J Palliat Care. 2020;26(1):42-6.

23. Haun MW, Sklenarova H, Brechtel A, Herzog W, Hartmann M. Distress in cancer patients and their caregivers and association with the caregivers' perception of dyadic communication. Oncol Res Treat. 2014;37(7-8):384-8.

24. Jeong A, An JY. The moderating role of social support on depression and anxiety for gastric cancer patients and their family caregivers. PLoS ONE. 2017;12(12): e0189808.

25. VanHoose L, Black LL, Doty K, Sabata D, Twumasi-Ankrah P, Taylor S, et al. An analysis of the distress thermometer problem list and distress in patients with cancer. Support Care Cancer Off $\mathrm{J}$ Multinatl Assoc Support Care Cancer. 2015;23(5):1225-32.

26. Ojewole F, Madu A, Nwozichi C. Association between psychological distress and unmet information needs among female cancer patients in two selected teaching hospitals in South-West Nigeria. CHRISMED J Health Res. 2018;5:11-17. 